\title{
O CONCEITO DE ESTADO NOS LIVROS DIDÁTICOS DE SOCIOLOGIA PARA O ENSINO MÉDIO
}

\author{
Renato Kendy Hidaka ${ }^{1}$, Rodrigo Moreira Vieira ${ }^{2}$. \\ ${ }^{1}$ Instituto Federal de Educação, Ciência e Tecnologia São Paulo - IFSP, ${ }^{2}$ Instituto Federal do Pará. E-mail: \\ rkhidaka@yahoo.com.br
}

\begin{abstract}
RESUMO
Este artigo tem como objetivo analisar as formas como o Estado é retratado nos livros didáticos de Sociologia para o ensino médio. Busca-se, mais especificamente, examinar se o Estado aparece como conteúdo sociológico nos livros didáticos e, em caso positivo, identifica-se os significados que Ihe são atribuídos; investiga-se se os livros realizam recortes conceituais fundamentados em autores ou fazem referência a uma corrente ou sistema teórico específico; identifica temas e conceitos relacionados à noção de Estado; verifica-se se existem diferentes tratamentos nos livros ou se há um consenso quanto às definições conceituais e autores citados. A pesquisa foi desenvolvida com base em metodologia qualitativa e emprega a técnica de Análise de Conteúdo categorial de Bardin. Utiliza como fonte documental de análise cinco dos seis livros didáticos de Sociologia aprovados pelo Programa Nacional do Livro e Material Didático de 2015: 1) Sociologia para o ensino médio, 2) Tempos modernos, tempos de Sociologia, 3) Sociologia hoje, 4) Sociologia para jovens no século XXI e 5) Sociologia. Conclui-se que o conceito de Estado está presente em todos os livros didáticos examinados. Cada livro apresenta intepretações diversas, com predomínio das definições de dois dos clássicos do pensamento sociológico, a saber, Marx e Weber. Conceitos como cidadania, poder e classe social aparecem relacionados ao conceito de Estado na maioria dos livros.
\end{abstract}

Palavras-chave: Estado; Sociologia; Livro didático; PNLD.

\section{THE CONCEPT OF STATE IN THE SOCIOLOGY'S TEXTBOOKS AT HIGH SCHOOL}

\begin{abstract}
The aim of this paper is to identify the ways in which the State is presented on sociology's textbooks at high school. More precisely, to assay if textbooks mention the State and how the referencing is done; to investigate whether books make conceptual clippings based on authors or refer to a theoretical system; check if there are different treatments in the books or if there is a consensus on the conceptual definitions and authors cited. This project was developed based on qualitative research. The documental source reviewed was composed of the six Sociology's textbooks approved by the Programa Nacional do Livro e Material Didático - 2015: 1) Sociologia para o ensino médio, 2) Tempos modernos, tempos de Sociologia, 3) Sociologia hoje, 4) Sociologia para jovens no século XXI e 5) Sociologia. The paper concludes that the concept of state is present in all textbooks examined. Each book presents diverse interpretations, with the predominance of the definitions of two of the classics of sociological thought, namely Marx and Weber. Concepts such as citizenship, power, and social class are related to the concept of state in most books.
\end{abstract}

Keywords: State; Sociology; Textbook; PNLD. 


\section{INTRODUÇÃO}

Estado é uma palavra que faz parte do vocabulário do senso comum e amplamente presente nos discursos políticos. Sem contar como uma definição unitária, os sentidos atribuídos ao termo são dependentes de circunstâncias de discurso particulares (CHARAUDEAU, 2016). No campo científico, a situação não é diferente. O signo Estado é investido de significados variados, dependendo da posição teórica que se assume.

Este artigo se insere no contexto de crescimento das pesquisas realizadas no interior do subcampo de pesquisa denominado ensino de Sociologia (BODART; SOUZA, 2017). Esse subcampo tem sua expansão associada, vale assinalar, ao retorno da Sociologia enquanto componente curricular obrigatório no ensino médio, possibilitado pela promulgação da Lei $n$. 11.684, de 2 de junho de 2008. Com o retorno da obrigatoriedade, a Sociologia foi incluída nas políticas governamentais voltadas ao currículo, à formação de professores e à produção de materiais didáticos (BRASIL, 2014).

Um dos fenômenos decorrentes dessa inclusão é expansão do mercado editorial de materiais didáticos direcionados à Sociologia. Com o crescimento das publicações, tem emergido o interesse de pesquisadores em analisar o conteúdo dos livros didáticos. A respeito desses livros, Handfas (2013) destaca que "suas páginas expressam ideias, valores e práticas pedagógicas difundidas em diferentes contextos educativos". Para Florêncio (2019, p.122), "os livros didáticos cumprem uma importante função no processo de ensinoaprendizagem, pois, dentre as diversas formas de divulgação do conhecimento científico, este se torna um dos principais orientadores do trabalho de professores e alunos.".

Com base nessas considerações, neste artigo, procuramos examinar a forma como os livros didáticos de Sociologia para o ensino médio abordam a noção de Estado. Partimos das seguintes perguntas: o Estado aparece como objeto de estudo nesses livros? Se sim, quais são as definições neles apresentadas?

\section{DELINEAMENTO METODOLÓGICO}

Esta é uma pesquisa qualitativa de análise documental que faz uso da técnica de Análise de Conteúdo categorial (BARDIN, 2002). Utiliza como fonte documental de análise cinco dos seis livros didáticos de Sociologia aprovados pelo Programa
Nacional do Livro e Material Didático (PNLD) 2015: 1) Sociologia para o ensino médio, 2) Tempos modernos, tempos de Sociologia, 3) Sociologia hoje, 4) Sociologia para jovens no século XXI e 5) Sociologia. ${ }^{1}$ O objetivo geral do trabalho consiste em examinar as formas como o Estado é retratado nos livros didáticos de Sociologia para o ensino médio. Mais especificamente, procura-se a) examinar se o Estado aparece como conteúdo sociológico nos livros didáticos e, em caso positivo, identifica-se os significados que lhe são atribuídos; b) investiga se os livros realizam recortes conceituais fundamentados em autores ou fazem referência a uma corrente ou sistema teórico; c) identifica temas e conceitos relacionados à noção de Estado; d) verifica se existem diferentes tratamentos nos livros ou se há um consenso quanto às definições conceituais e autores citados.

Esclareça-se que a escolha dos livros não seguiu qualquer tipo de critério pré-estabelecido. A escolha dos cinco livros se deu de maneira aleatória, não havendo, assim, qualquer manobra ideológica que tivesse o intuito de privilegiar ou preterir um ou outro livro. O mesmo se observa para a ordem de exposição.

\section{RESULTADOS E DISCUSSÃO}

Iniciemos com Sociologia para o Ensino Médio, que é uma das duas obras que consta entre os livros didáticos aprovados pelo PNLD desde a primeira edição que a Sociologia participou do programa. Escrito por Nelson Dacio Tomazi, professor aposentado do departamento de Ciências Sociais da Universidade Estadual de Londrina, o livro tem seu conteúdo dividido em sete unidades temáticas, contando também com uma introdução e um apêndice, que narra a história da Sociologia. Cada unidade do livro apresenta de três a quatro capítulos, cada um deles abordando um subtema específico. As temáticas das unidades podem ser inferidas pelos seus títulos, a saber: 1. A sociedade dos indivíduos, 2. Trabalho e sociedade, 3. A estrutura social $e$ as desigualdades, 4. Poder, política $e$ Estado, 5. Direitos, cidadania e movimentos sociais, 6. Cultura e ideologia e 7. Mudança social.

A noção de Estado, objeto de nossa investigação, é abordada na unidade 4. Essa

\footnotetext{
${ }^{1}$ Todos os livros se apresentam em um único volume para as três séries do ensino médio.
} 
unidade é constituída por quatro capítulos: o capítulo 10, intitulado $O$ Estado moderno, o 11,0 poder e o Estado, o 12, Poder, política e o Estado no Brasil e o 13, A democracia no Brasil. O termo Estado, como se pode constatar, aparece no título de três dos quatro capítulos da unidade. Logo, já pelos títulos é possível inferir que o Estado é compreendido, no livro, como objeto de estudo sociológico.

O capítulo 10 inicia com uma discussão sobre o processo de formação do "Estado moderno". Contudo, ao longo do capítulo, não encontramos qualquer definição acerca do conceito de Estado, bem como não verificamos qualquer explicação sobre o significado do adjetivo "moderno". O que temos é uma explanação sobre sua emergência na história. 0 "Estado moderno" teria surgido com a desintegração do mundo feudal, a partir de um processo que caracterizado pela concentração e centralização:

das Forças Armadas e do monopólio da violência; da estrutura jurídica; da cobrança de impostos um signo do poder $\mathrm{e}$, ao mesmo tempo, o meio de assegurar a manutenção das Forças Armadas, da burocracia e do corpo jurídico; de um corpo burocrático para administrar o patrimônio público, como as estradas, os portos, o sistema educacional, a saúde, o transporte, as comunicações e outros tantos setores. (TOMAZI, 2013, p. 130)

Após explicitar os acontecimentos históricos que contribuíram para a formação do Estado moderno, são apresentadas as particularidades do "Estado absolutista", do "Estado liberal", do "Estado soviético", do "Estado fascista", do "Estado de bem-estar social" e do "Estado neoliberal". Tomazi não explicita se estes são tipos ou formas do Estado moderno, ainda que suas considerações posteriores levem o leitor a pressupor que sim ou seja, que tais formas são variações assumidas pelo Estado moderno em determinadas sociedades ao longo de sua história.
Vejamos então como o autor diferencia essas formas do Estado moderno. No Estado absolutista, o poder político é centralizado. O Estado é a entidade que controla as atividades econômicas, intervindo na concessão de monopólios, na fixação de tarifas e preços e na administra da moeda; controla também o exército e a justiça. A monarquia portuguesa do final do século XIV e a monarquia de Luís XIV, na França, seriam exemplos históricos dessa forma absolutista. Thomas Hobbes (1588-1679) e Jacques Bossuet (1627-1704) aparecem como referência de intelectuais que fundamentaram a necessidade do Estado absolutista.

O Estado liberal teria surgido como reação ao absolutismo. Entre seus princípios se encontram a valorização do individualismo, a garantia da liberdade econômica e a defesa da propriedade privada. As bases teóricas do liberalismo estão contidas na obra de Adam Smith (1723-1790).

Já o Estado soviético e o Estado fascista têm sua emergência histórica concreta nas primeiras décadas do século $X X$, surgidos enquanto alternativa à crise social e econômica que abalaram as estruturas do Estado liberal. 0 primeiro foi implantado após a Revolução Russa, organizado a partir de princípios socialistas, tais como a propriedade coletiva e a produção econômica planificada. O Estado soviético, salienta Tomazi, chegou a congregar quinze "repúblicas unidas" em 1956.

O Estado fascista desenvolveu-se na Itália, na Alemanha e em outros países da Europa. Entre os fundamentos do fascismo estão a ideia de uma comunidade nacional que compartilha do mesmo destino e o princípio de autoridade e hierarquia.

O Estado de Bem-Estar Social, enquanto teoria, teria surgido como alternativa de organização estatal para combater tanto a crise de 1929 quanto o movimento de trabalhadores e a ideologia socialista. Teve seu ápice no pósSegunda guerra nos EUA e em diversos países da Europa. Ele caracteriza-se pela intervenção estatal na economia, seja regulando e subsidiando as atividades econômicas, seja executando grandes investimentos, e pela política social de redistribuição de renda. O seu principal teórico foi John Maynard Keynes (18831946).

Por fim, temos o Estado neoliberal, que desponta com a crise capitalista na década de 1970. Este foi adotado inicialmente por 
Margareth Thatcher, na Inglaterra, e por Ronald Reagan, nos Estado Unidos. Os postulados do Estado neoliberal são a não intervenção do Estado na economia, a privatização e a ideia de que o bem-estar dos cidadãos deve ficar por conta deles mesmos (TOMAZI, 2013).

No capítulo 11 encontramos algumas definições sociológicas a respeito do Estado. Nele, Tomazi nos apresenta as definições dos clássicos da Sociologia, iniciando com Karl Marx. Destaca que este não formulou uma teoria específica sobre o Estado. No entanto, sustenta que algumas de suas obras possuem considerações a respeito do assunto. Na obra $A$ ideologia alemã, manuscrito produzido em parceria com F. Engels, em 1846, Tomazi aponta:

Marx identificou a divisão do trabalho e a propriedade privada, geradoras das classes sociais, como a base do surgimento do Estado, que seria a expressão jurídicopolítica da sociedade burguesa. A organização estatal apenas garantiria as condições gerais da produção capitalista, não interferindo nas relações econômicas (Ibid., p. 141).

Ainda segundo o autor, no Manifesto comunista, de 1848, Marx e Engels assinalam que "os dirigentes do Estado moderno funcionam como um comitê executivo da classe dominante (a burguesia)" (Ibid., p. 142). E em As lutas de classe na França e em O Dezoito Brumário de Luís Bonaparte, "Marx declara que o Estado nasceu para refrear os antagonismos de classe e, por isso, favorecer a classe dominante." (Ibid. p. 142). Próximos de uma leitura anarquista, o Estado, em Marx, enquanto forma de dominação de classe, deixaria de existir com a tomada do poder político por parte dos trabalhadores organizados. Impõe-se destacar que Tomazi não faz referência ao conceito de socialismo e nem ao de comunismo, como veremos em outros livros didáticos.

A exposição segue com a abordagem da concepção de Émile Durkheim. Para Tomazi, em Durkheim, o Estado possui uma função eminentemente moral e atua sobre o indivíduo com vistas à sua integração social. Um excerto da obra Lições de Sociologia é citado. Destacamos a passagem abaixo:
Eis o que define o Estado. É um grupo de funcionários sui generis, no seio do qual se elaboram representações e volições que envolvem a coletividade, embora não sejam a coletividade. [...] Ele só é a sede de uma consciência especial, restrita, porém mais elevada, mais clara, que tem de si mesma um sentimento mais vivo. [...] Podemos então dizer em resumo: o Estado é um órgão especial encarregado de elaborar certas representações que valem para a coletividade. Essas representações distinguem-se das outras representações coletivas por seu maior grau de consciência e de reflexão. (DURKHEIM apud TOMAZI, 2013, p. 144).

Por fim, se apresenta a definição de Max Weber, para quem "o Estado é uma relação de dominação entre homens mediante a violência, que é considerada legítima, e por meio de uma associação compulsória que organiza esta dominação". Conforme Tomazi (Ibid., p. 145): "Para Weber, [...] o Estado é uma das muitas organizações burocráticas da sociedade, sem conteúdo próprio". A esse respeito, encontramos uma passagem de Ensaios de Sociologia, na qual Weber afirma:

Sociologicamente, o Estado não pode ser definido em termos de seus fins. Dificilmente haverá qualquer tarefa que uma associação política não tenha tomado em suas mãos, e não há tarefa que se possa dizer que tenha sido sempre, exclusivamente

peculiarmente, das associações designadas como políticas: hoje o Estado, ou, historicamente, as associações que foram predecessoras do Estado moderno. Em última 
análise, só podemos definir o Estado moderno sociologicamente em termos dos meios específicos peculiares a ele, como peculiares a toda associação política, ou seja, o uso da força física. (WEBER apud TOMAZI, 2013, p. 146).

Depois de expor esse conjunto de definições sobre o Estado baseadas nos clássicos da Sociologia, o livro se ocupa da relação entre Estado moderno e democracia. Nesse sentido, destaca-se a observação de que a concepção de participação política popular foi inserida por meio de lutas no âmbito do Estado liberal, não sendoIhe um princípio de origem. No final do capítulo, é apresentado o conceito de Estado de exceção, desenvolvido por G. Agamben. Em sua definição, Estado de exceção significa "a suspensão do ordenamento jurídico: a anulação dos direitos civis do cidadão e seu estatuto jurídico como indivíduo." (Ibidem., p. 153). A tese de Agamben é a de que esta forma de Estado, de medida excepcional, tornou-se, na política contemporânea, uma técnica permanente de governo.

No capítulo 12, a atenção recai sobre as formas assumidas pelo Estado brasileiro no decurso histórico. De colônia portuguesa, assumimos a forma de Estado monárquico do tipo liberal, com a independência em 1822. Em seguida, com a proclamação da república, temos a forma republicana de tipo oligárquico (18891930) e, posteriormente, variações entre um Estado ditatorial e um Estado liberal. Com o fim da ditadura militar, em 1985, o Estado brasileiro assume a forma liberal democrática. Nos governos Collor e Fernando Henrique Cardoso, adota-se a forma neoliberal, cujas principais características, de acordo com Tomazi, são: adoção de políticas privatistas, abertura econômica, renúncia do controle da moeda e da política cambial, desregulamentação do mercado de trabalho e incentivo ao setor privado de saúde e educação. Os governos Lula e Dilma teriam mantido a política econômica do governo anterior, com a ampliação de políticas de redistribuição de renda, como o aumento do salário mínimo e a implementação de programas como o Fome Zero e o Bolsa Família.

No capítulo 13, o subtema abordado é a democracia no Brasil. A noção de Estado aparece aqui ao se afirmar que uma das características do Estado no Brasil é a sua sobreposição à sociedade, fenômeno expresso na relação que se estabelece entre público e privado ou, mais precisamente, pela apropriação privada do que é público. Essa característica teria como implicação a produção de fenômenos como o clientelismo, o nepotismo, a corrupção e a despolitização da população.

Encerrado o primeiro livro, passemos agora para Tempos modernos, tempos de Sociologia. Assim como o anterior, este livro didático também consta entre os materiais aprovados desde o PNLD 2012. Circula nas escolas públicas, portanto, desde a primeira edição do programa do governo. Foi escrito por Helena Bomeny - doutora em Sociologia e professora da Universidade do Estado do Rio de Janeiro -, Bianoa Freire-Medeiros - doutora em História e Teoria da Arte e da Arquitetura e professora da Escola Superior de Ciências Sociais da FGV -, Raquel Balmant Emerique - doutora em Ciências Sociais e pesquisadora do Programa FGV Ensino Médio - e Julia Galli O'Donnell - doutora em Antropologia Social e professora da Escola Superior de Ciências Sociais da FGV. No que se refere ao conteúdo, é dividido em três partes. A parte 1, intitulada de Saberes cruzados, conta com uma introdução e quatro capítulos. Neles, são abordados o surgimento da modernidade e o desenvolvimento da Antropologia, da Ciência Política e da Sociologia. A parte 2 , A Sociologia vai ao cinema, e a parte 3, A Sociologia vem ao Brasil, também abrem com uma introdução, mas são formadas por oito capítulos cada uma. A parte 2 trata de temas como a divisão do trabalho social, a vida nas cidades, o mundo do trabalho, as formas de poder, entre outros. Para cada um desses temas, são apresentadas as reflexões de autores vinculado às Ciências Sociais, como Durkheim, Marx, Tocqueville, Foucault, Elias e Benjamin. A parte 3 tem como enfoque a análise da sociedade brasileira contemporânea, aspectos do mundo do trabalho, da vida religiosa, da cultura, da violência e do consumo no Brasil são evidenciados, com dados e interpretação sociológica.

A noção de Estado é empregada em diversos capítulos do livro, mas de maneira esparsa, como veremos. No capítulo 4, intitulado Saber sobre a astúcia e as manhas da política, da parte 1 , as autoras partem do conceito weberiano de poder para desenvolverem uma discussão sobre a política. O termo Estado é 
utilizado na definição do objeto de estudo da Ciência Política. Segundo as autoras, este ramo das Ciências Sociais "se interessa pelo estudo do exercício do poder em suas variadas formas de manifestação e também em entender o movimento da sociedade para fazer valer sua vontade diante do Estado." (BOMENY et al., 2013 , p. 55). Ainda no mesmo capítulo, na seção Tempos modernos e a nova ordem política, Maquiavel é mencionado como um dos grandes nomes da Ciência Política. O Estado, nesse contexto, é destacado como objeto da política. Conforme as autoras, para Maquiavel, a "finalidade da política seria a manutenção do Estado." E complementam: "Tudo, portanto, que dissesse respeito ao funcionamento do Estado ato de governar, de obedecer, de administrar conflitos, de se representar - interessava ao conhecimento da política." (BOMENY et al., 2013, p.55).

Outra menção ao Estado é encontrada na seção Democracia e Ciência Política no Brasil, na qual, ao tratar do coronelismo, enquanto fenômeno presente no sistema político na Primeira República, diz-se que ele é caracterizado pela relação de troca de favores entre o Estado, os chefes locais e os trabalhadores rurais. Uma última menção, no capítulo, é feita na seção $A s$ políticas públicas. Destaquemos o trecho no qual a referência é realizada:

A função que o Estado desempenha em nossa sociedade sofreu inúmeras transformações com o passar do tempo. Nos séculos XVIII e XIX, seu principal objetivo era a segurança pública e a defesa externa em caso de ataque inimigo.

Entretanto, com o aprofundamento e expansão da democracia, as responsabilidades do Estado se diversificaram. Atualmente, é comum se afirmar que a função do Estado é promover o bemestar da sociedade. (BOMENY et al., 2013, p. 64)

Notemos que, diferentemente do livro didático anteriormente examinado, o termo Estado não aparece aqui adjetivado. Também não se faz referência às suas diferentes formas.
Encontraremos a noção Estado de BemEstar Social na seção introdutória à parte 3 , denominada Sociologia e cinema, na qual as autoras contextualizam a produção do filme Tempos Modernos, de C. Chaplin. O Estado de Bem-Estar Social aparece como um fenômeno surgido no pós-Segunda Guerra, com base nas políticas de intervenção econômica e programas de ajuda social, implementados no combate à Grande Depressão (Ibid., p. 73). Todavia, não há uma preocupação com a sua definição conceitual.

No capítulo 8, Trabalhadores, uni-vos!, veremos o emprego da noção de Estado socialista, no texto em que as autoras fazem uma breve biografia de Marx. Estado socialista aparece como fenômeno histórico constituído com base nas ideias de Marx. Mais à frente, o termo Estado aparece na definição do conceito de socialismo: "esse modelo de organização social propõe a extinção da propriedade privada dos meios de produção, a tomada do poder pelo proletariado, o controle do Estado e a divisão igualitária da renda" (BOMENY et al., 2013, p. 121). Na seção Leitura complementar, nos deparamos com o termo "Estado burguês", num excerto retirado do Manifesto Comunista, de Marx e Engels, mas há uma definição do que isso seja.

No capítulo 14, Brasil, mostra a tua cara!, o Estado aparece como a entidade que assegura os meios de sobrevivência da população indígena. No capítulo 16, O Brasil ainda é um país católico, ao discutir a relação entre Estado e liberdade religiosa, as autoras afirmam: "o Estado tem de garantir essa liberdade e dar segurança aos fiéis para que vivam livremente sua religiosidade." (BOMENY et al., 2013, p. 256). Em seguida, em um trecho retirado do preâmbulo da Constituição brasileira, encontramos o conceito de "Estado Democrático", que é definido pela sua função de "assegurar o exercício dos direitos sociais e individuais, a liberdade, a segurança, o bem-estar, o desenvolvimento, a igualdade e a justiça" (BOMENY et al., 2013, p. 256).

No capítulo 18, Desigualdades de várias ordens, ao discutir as diferentes formas de desigualdade social existente no Brasil, faz-se referência, novamente, à noção de Estado de Bem-Estar Social, empregada como exemplo de "modelo político" adotado em alguns países da Europa, na América do Norte e no Brasil, com o intuito de corrigir as desigualdades sociais. $\mathrm{O}$ Estado de Bem-Estar Social, conforme as autoras, está associado à uma forma de organização que 
visa a garantia e promoção de direitos sociais (BOMENY et al., 2013, p. 279).

No capítulo 19, Participação política, direitos e democracia, o Estado é concebido enquanto um ente guiado pela Constituição, entendida esta como "procedimentos, regras, normas, autorizações e proibições" (BOMENY et al., 2013, p. 300). Ainda neste capítulo, ao relacionar democracia e liberalismo, as autoras recorrem a N. Bobbio para asseverar que o "Estado contemporâneo surgiu da necessidade, por um lado de limitar o poder e, por outro, de distribuí-lo. Assim, esse Estado combinou uma forma de governo - a democracia - uma teoria do Estado - o liberalismo - na chamada democracia liberal". E concluem: "Para os liberais, o Estado é um mal necessário. Ele é indispensável para coibir a perversidade natural dos homens, mas, ao fazê-lo, restringe a liberdade dos indivíduos. Por isso, o Estado deve ter seus poderes e suas funções limitadas." (BOMENY et al., 2013, p. 305).

No capítulo 20, Violência, crime e justiça no Brasil, ao abordar o tema da violência no Brasil, utiliza-se o conceito weberiano de Estado. Conforme as autoras, o Estado, em Weber, é compreendido como "uma comunidade humana que pretende, com êxito, o monopólio do uso legítimo da força física dentro de determinado território" (BOMENY et al., 2013, p. 322). Nessa perspectiva, ele tem sua violência legitimada por se ancorar no conjunto de normas e leis consideradas legitimas pelos indivíduos pertencentes à sociedade. Esse conceito de Weber também é acionado para problematizar a atuação do Estado brasileiro:

Você já deve ter ouvido dizer ou lido que o Estado brasileiro não detém mais o monopólio da força; que os aparelhos estatais de controle social, como a política e a justiça, têm perdido sua capacidade de controle por contarem com servidores mal remunerados, mal preparados e muitas vezes corruptos. Há quem argumente que o Estado não tem mais capacidade nem de conter 0 crime, nem de fazer valer a ordem. Conclui-se, assim, que os bandos criminosos bem armados e sempre violentos, constituiriam um "Estado paralelo" ou um "paraestado". Até que ponto essa linha de raciocínio se sustenta? (BOMENY et al., 2013, p. 322).
No capítulo 22, Interpretando o Brasil, evidencia-se a interpretação de Sérgio Buarque de Holanda. Tal perspectiva sustenta, ancorada nas formulações de Weber, que um dos traços problemáticos do Estado brasileiro é a presença do patrimonialismo. Sobre esse fenômeno, afirma-se:

Numa sociedade em que impera a lógica legalburocrática, o Estado é regido pela impessoalidade, pelo formalismo, pela previsibilidade e pela universalidade dos critérios. Numa sociedade organizada segundo 0 patrimonialismo, ao contrário, os homens públicos atuam na esfera de acordo com regras e valores da esfera doméstica. (BOMENY et al., 2013, p. 349).

Prosseguindo nossa análise, passemos agora para o livro Sociologia Hoje. Constando pela primeira vez entre os livros didáticos aprovados pelo PNLD na edição de 2015, este material tem como autores Igor José de Renó Machado, Henrique Amorim e Celso Rocha de Barros, os três formados em Ciências Sociais, da graduação à pós-graduação. Os dois primeiros são professores universitários, um vinculado ao departamento de Ciências Sociais da Ufscar e o outro, ao departamento de Ciências Sociais da Unicamp. O livro em questão apresenta uma divisão do conteúdo bastante homogênea, distribuído em três grandes unidades que comportam cinco capítulos cada. A unidade 1 tem como título Cultura, a unidade 2, Sociedade, e a unidade 3, Poder e cidadania. Essa divisão, notadamente, faz referência às disciplinas que compõem às Ciências Sociais, que são, respectivamente, a Antropologia, a Sociologia e a Ciência Política, como assinalado pelos autores. ${ }^{2}$

O Estado, enquanto objeto de conhecimento, recebe atenção na unidade 3 , que, como assinalamos, se ocupa do conhecimento produzido no campo da Ciência Política. No primeiro capítulo da unidade,

\footnotetext{
${ }^{2} \mathrm{Na}$ Introdução, encontra-se uma breve apresentação das Ciências Sociais na qual procura-se caracterizar a particularidade dos objetos de estudo pertinentes à Antropologia, à Sociologia e à Ciência Política.
} 
intitulado Política, poder e Estado, os autores asseveram que o Estado é tema de boa parte dos trabalhos desenvolvidos na área. Destacam, ainda, que a definição de Estado mais utilizada pelos especialistas é a de Weber, segundo a qual "o Estado é o monopólio da violência legítima em um determinado território." (MACHADO; AMORIM; BARROS, 2013, p. 213, grifos dos autores). O exemplo dado para dar sustentação à formulação weberiana é o da violência praticada pela polícia no cumprimento das leis.

Ainda no capítulo, os autores utilizam as contribuições de Charles Tilly para discorrerem sobre a formação dos "Estados modernos". Observam, a esse respeito, que na origem do Estado encontra-se a guerra e a conquista e, no processo de consolidação, confrontos e concessões. De acordo com os autores, os Estados modernos têm sua origem no final da Idade Média, em um processo marcado pela concentração de poder dos reis. Para se consolidarem, os governantes desses Estados tiveram que extirpar os exércitos particulares da nobreza, oferecer vantagens econômicas à burguesia, que financiava o governo, e conceder direitos ao povo, a fim de evitar rebeliões. (MACHADO; AMORIM; BARROS, 2013, p. 216).

Entre os pensadores da fundação do Estado, menciona-se Maquiavel e os contratualistas, mais precisamente, Hobbes, Locke e Rousseau. Para os contratualistas, a reflexão sobre a fundação do Estado parte da pergunta de como seria a vida sem o Estado. Os três autores mencionados partem da pressuposição de um estado de natureza para, então, argumentarem em favor da necessidade da constituição do Estado. Em Hobbes, o que teria levado à fundação do Estado foi o medo. Os homens teriam renunciado à sua liberdade, concordando em obedecer ao governante do Estado, em nome de sua segurança. A função do Estado, em Hobbes, consiste na garantia da paz e da obediência às leis. Por sua vez, Locke parte do pressuposto de que os homens no estado de natureza eram possuidores natos do direito à liberdade e à propriedade. A existência do Estado viria da necessidade de que tais direitos fossem assegurados em eventuais conflitos entre os homens. A não preservação, pelo Estado, dos direitos à liberdade e à propriedade, daria aos homens o direito de se rebelar contra o mesmo. Em Rousseau, os homens no estado de natureza eram livres e felizes. É a invenção da propriedade e a necessidade de protegê-la que cria a necessidade do Estado. De acordo com Machado, Amorim e Barros, para Rousseau, o "Estado mereceria ser considerado legítimo quando as leis fossem criadas pela Vontade Geral, que é a vontade do conjunto dos cidadãos que visa ao bem comum. Se pensarmos somente em nós mesmos ao escrever as leis, o Estado funcionará mal, e aos poucos acabaremos perdendo nossa liberdade." (MACHADO; AMORIM; BARROS, 2013 , p. 217, grifo dos autores). Os autores, de forma sucinta, finalizam destacando a importância dos contratualistas para o entendimento da política e do Estado:

Hobbes formulou uma justificativa consistente para a existência do Estado, e suas ideias sempre voltam à tona quando a ordem pública está seriamente ameaçada (por exemplo, quando há uma guerra civil, ou um surto de violência). Locke foi o primeiro grande defensor moderno da liberdade e dos direitos do cidadão, tanto políticos quanto econômicos. E Rousseau discutiu com especial competência as questões da democracia e da igualdade. (MACHADO; AMORIM; BARROS, 2013, p. 218).

No capítulo 12, Globalização e política, ao abordar o tema da governança global, destaca-se que aquilo que se considera uma das principais características dos Estados modernos: a sua variedade - posto que não existe um "Estado Global". Essa característica, segundo os autores, faz com que os Estados soberanos, ao se relacionarem, necessitem "negociar suas diferenças e se organizar para enfrentar problemas que afetam mais de um Estado" (MACHADO; AMORIM; BARROS, 2013, p.2 30). Aqui, introduz-se o conceito de "governança global", que traduz o processo de negociação, mediado por instituições e regras globais, entre diferentes Estados.

No capítulo 13, A Sociedade diante do Estado, encontramos uma última referência à noção de Estado. A partir de conceitos como cidadania, movimentos sociais, capital social e revolução, empreende-se no capítulo a reflexão sobre a relação entre Estado e agentes sociais. 
Entre outras coisas, afirma-se, por exemplo, que a sobrevivência do Estado está vinculada às concessões e aos acordos que realiza com os diversos grupos sociais. Estes, por sua vez, se posicionam diante do Estado reivindicando direitos e garantias. Por fim, aponta-se que "As tentativas do Estado nem sempre têm êxito, o que, em alguns casos, pode até mesmo levar à derrubada violenta do governo" (MACHADO; AMORIM; BARROS, 2013, p. 246).

Passemos, então, para o próximo livro. Sociologia para jovens no século XXI, escrito por Luiz Fernandes de Oliveira e Ricardo Cesar Rocha da Costa, ambos com formação na área de Sociologia e/ou Ciências Sociais e com experiência docente no ensino médio e no ensino superior, consta pela primeira vez entre as obras aprovados no PNLD de 2015. Como o livro didático anterior, é formado por três grandes unidades. No entanto, difere-se pelo conteúdo e pela sua distribuição nessas unidades. Estas são intituladas, respectivamente: 1 . Sociedade $e$ conhecimento sociológico, 2. Trabalho, política e sociedade e 3. Relações sociais contemporâneas. A primeira possui oito capítulos e as demais, sete cada.

O Estado, enquanto objeto de estudo, aparece na unidade 2. Primeiramente, o termo é mencionado no capítulo 13 , denominado "É de papel ou é pra valer?" Cidadania e direitos no mundo e no Brasil contemporâneo, quando, ao conceituar "cidadão", diz-se que é "aquele que está no gozo dos direitos civis e políticos de um Estado." (OLIVEIRA; COSTA, 2013, p. 194). Em seguida, a noção de Estado Bem-estar Social será empregada para dar visibilidade às contribuições de T.H. Marshall. O Estado de Bem-Estar Social é apresentado como um exemplo de "sistema econômico, político e social ideal, o único capaz de garantir verdadeiramente a prosperidade e uma vida segura, livre e igualitária para todos os cidadãos" (OLIVEIRA; COSTA, 2013, p. 197). No capítulo, o conceito de Estado é relacionado ao conceito de cidadania, no sentido de entidade que garante a efetividade dos direitos civis, políticos e sociais.

No capítulo 14, "O Estado sou eu." Democracia e Estado, Oliveira e Costa iniciam fazendo a diferenciação entre absolutismo e Estado, na sua forma atual. Para tanto, utilizam a frase do título, atribuída ao rei Luiz XIV, da França, como exemplo de absolutismo, indagando se ela poderia ser proferida pelos expresidentes brasileiros Fernando Henrique
Cardoso e Luiz Inácio Lula da Silva. A seguinte definição é apresentada: "O Estado, hoje, é uma estrutura organizada que, através de leis, rege a vida em sociedade. Deus não elege ninguém para comandar os indivíduos" (OLIVEIRA; COSTA, 2013 , p. 212). Embora não se faça menção ao conceito de Estado teocrático, impõe-se assinalar que a segunda frase da citação tem relação com esse conceito.

Ao levantarem a pergunta: "que ideia é essa de Estado no mundo moderno?", Oliveira e Costa respondem:

O Estado moderno se
caracteriza por um
conjunto de instituições,
que regem, através da
chamada ordem jurídica, o
funcionamento da
sociedade. A ordem
jurídica é constituída por
um leque de normas
aplicadas pelo Estado e
reconhecidas, em geral,
por todos os cidadãos.
O Estado compreende
basicamente três funções:
- elaborar leis;
- administrar os serviços
públicos e executar as leis;
- julgar a aplicação das
leis, quando estas não
estiverem sendo
devidamente cumpridas.
(OLIVEIRA; cosTA, 2013;
p. 212)

Com base nessas funções, segue-se a colocação de que o Estado moderno se divide em três poderes: o Executivo, o Legislativo e o Judiciário. Weber é citado como um dos intelectuais que, no campo da sociologia, discutiu a questão do Estado. De acordo com Oliveira e Costa, para o sociólogo alemão, o Estado se constitui enquanto um "aparato administrativo destinado à prestação de serviços e o exercício do monopólio legítimo da força" (WEBER apud OLIVEIRA; COSTA, 2013, p. 212). Com o termo aparato administrativo, explicam, Weber tem em vista tanto o corpo de funcionários públicos quanto o conjunto de recursos materiais e regras que regem o funcionamento das instituições estatais. Já a expressão "monopólio legítimo da força" significa, para Weber, o emprego legítimo da coerção que o Estado dispõe, seja mediante a criação e aplicação de leis, seja pelo uso de armas e acionamento do exército. Com base em Weber, 
afirma-se: "O Estado, portanto, é a única instituição social reconhecida por todos como 'legitima' no sentido de aplicar a lei ou, se esta não for obedecida, a força" (OLIVEIRA; COSTA, 2013, p. 212). Ele, o Estado, acaba por exercer uma forma de dominação legal, conforme a teoria weberiana.

Atentando para a confusão existente no senso comum entre governo e Estado, Oliveira e Costa resumem:

Estado: é um conjunto de instituições permanentes, distribuídas entre os poderes Executivo, Legislativo e Judiciário. Estes, segundo suas atribuições específicas, servem de "suporte" legal para o funcionamento da sociedade.

Governo: é uma ação política e administrativa vinculada principalmente ao Poder Executivo. A ação do governo é orientada por um conjunto de programas e projetos, apresentados por um ou mais partidos políticos no caso das democracias representativas [...]. (OLIVEIRA; COSTA, 2013, p. 214).

Outra definição de Estado apresentada no livro é a de Marx e Engels. Para estes, segundo os autores, o Estado teria surgido na História como o resultado da luta entre classes sociais. Ele seria decorrente da necessidade de as classes economicamente dominantes assegurarem a dominação política, a repressão e a exploração sobre as classes dominadas. Com base em Engels, afirma-se que o Estado não opera simplesmente como um instrumento das classes dominantes. Em determinados momentos históricos, ele pode se tornar um mediador dos conflitos de classe. (Ibid., p. 216). Os autores encerram a discussão sobre Estado e seguem com uma exposição sobre formas de governo.

Temos agora o último livro a ser analisado: Sociologia, que tem como autoras Silvia Maria de Araújo, Maria Aparecida Bridi e Benilde Lenzi Motim, todas professoras universitárias em cursos de graduação e pósgraduação em Sociologia e/ou Ciências Sociais. Esse livro, como os dois últimos, também consta pela primeira vez entre no PNLD 2015. No que diz respeito ao conteúdo, diferentemente dos demais, este livro não se apresenta dividido em unidades. Ele é composto por onze capítulos, cada qual abordando uma temática específica. $\mathrm{O}$ capítulo 1 é denominado Viver na sociedade contemporânea: a Sociologia se faz presente; o capítulo 2, Sociologia: uma ciência da modernidade; o capítulo 3, A família no mundo de hoje; o capítulo 4, Trabalho e mudanças sociais; o 5, A cultura e suas transformações; o 6 , Sociedade e religião; o 7, Cidadania, política e Estado; o 8, Movimentos sociais; o 9, Educação, escola e transformação social; o 10, Juventude, uma invenção da sociedade; o 11, 0 ambiente como questão global.

Constante no capítulo 7, o Estado segue como tema de estudo logo após a discussão sobre a noção de cidadania. Afirma-se a seu respeito que: "Por meio de políticas públicas, o Estado intervém em diferentes dimensões da sociedade. Por vezes, aspectos econômicos e sociais se confundem nessa intervenção estatal" (ARAÚJO; BRIDI; MOTIM, 2013, p. 176). Em seguida, as autoras comparam a ação do Estado nas sociedades socialistas e nas sociedades capitalistas. Nas sociedades socialistas, aquele, por meio de políticas públicas, assumiria integralmente as necessidades da população. Nas sociedades capitalistas, ele se atentaria fundamentalmente para as necessidades sociais básicas, como educação, segurança e saúde.

Em outra seção do capítulo, encontramos que: "Desde a Idade Moderna, o exercício do poder legítimo é considerado em nossa sociedade uma atividade própria do Estado" (ARAÚJO; BRIDI; MOTIM, 2013, p. 186). A base para essa concepção, diferentemente dos outros livros didáticos que procuram se fundamentar em Weber, é atribuída a Maquiavel.

Araújo, Bridi e Motim apontam que a função do Estado é assegurar, por meio de políticas públicas, "certas condições de vida que a sociedade considera necessárias à população". Todavia, relativizam a definição acima ao assinalarem que: "Não há, no entanto, unanimidade quanto ao papel dessa instituição social, tampouco quanto às interpretações teóricas a respeito dela. É fato que esse é um tema controverso." (ARAÚJO; BRIDI; MOTIM, 2013 , p. 187). Atente-se, aqui, que, não obstante os outros livros didáticos apresentarem mais de uma definição acerca do Estado, Sociologia é o 
único livro que textualmente declara a existência de interpretações controversas sobre o assunto.

O livro expõe, em seguida, a definição de Engels sobre o Estado. De acordo com as autoras, para Engels, o papel do Estado é amortecer os conflitos sociais entre as classes, assegurando a reprodução do sistema. Além da definição de Engels, apresenta, ainda, algumas breves considerações a respeito das definições de Marx, Weber, Gramsci, Althusser, Poulantzas e lanni. Para Marx, o Estado é compreendido como parte da superestrutura da sociedade, formada pelas instâncias jurídico-política e ideológica. Para Weber, o Estado é concebido como uma relação de dominação na qual um grupo dominante tem o poder, reconhecido como legítimo, de exercer a violência. Para Gramsci, o Estado assegura a dominação de classe não apenas pela coerção, mas também pela organização do consentimento, atuando no campo da cultura e da ideologia. Para Althusser, o Estado é conformado por aparelhos ou instituições sociais, como o exército, o sistema judiciário, etc., que têm como função a repressão - cuja finalidade é a manutenção da ordem social. Em Poulantzas, o Estado é compreendido como uma relação de forças entre classes sociais. Por fim, para lanni o Estado não corresponde unicamente aos interesses da classe dominante, fazendo parte do jogo complexo de interesses sociais (ARAÚJO; BRIDI; MOTIM, 2013, p. 189).

Depois de apresentar essas diferentes formas de interpretação do Estado, Araújo, Bridi e Motim tratam dos conceitos de Estado de BemEstar Social e de Estado neoliberal. De acordo com as autoras, essas são as duas formas de atuação do Estado que mais se sobressaíram no século XX. O Estado de Bem-Estar Social é caracterizado pela sua forma de atuação visando a garantia da seguridade social e da proteção dos indivíduos contra as adversidades do mercado. Já o Estado neoliberal tem como característica a mínima intervenção nas relações econômicas e no mundo do trabalho (ARAÚJO; BRIDI; MOTIM, 2013, 192).

\section{CONCLUSÕES}

Ao analisar os cinco livros didáticos de Sociologia, podemos concluir que em todos a noção de Estado se faz presente. Sociologia para o Ensino Médio, de Tomazi, prioriza as definições dos clássicos da Sociologia. Diferentemente dos outros livros, sustenta que há, em Marx, diferentes interpretações sobre o Estado em suas obras. Conceitos como Estado moderno, Estado absolutista, Estado liberal, Estado soviético, Estado fascista, Estado de bem-estar social, Estado neoliberal e Estado de Exceção são apresentados ao leitor, sendo associados a nomes como Hobbes, Bossuet, Smith, Keynes e Agamben. $O$ patrimonialismo é um dos fenômenos relacionados, na obra, ao Estado brasileiro. Em Tempos modernos, tempos de sociologia, a noção de Estado não é objeto de um capítulo específico, como nos demais. Ela é abordada nas seções de diferentes capítulos. A definição de Weber é priorizada na obra, mas encontramos também as definições de Marx e Bobbio. Termos como Estado de bem-estar social, Estado burguês, Estado democrático são empregados. Patrimonialismo e coronelismo são destacados como fenômenos relacionados ao Estado brasileiro. Em Sociologia hoje, realça-se que o Estado é um dos principais objetos de pesquisa da Ciência Política. No livro, a perspectiva weberiana também é priorizada na abordagem do tema. São utilizadas as reflexões de Tilly, ao tratar da história do Estado moderno, e a de Hobbes, Locke e Rousseau, como exemplos de teorias que dão base à fundação do Estado. Apresenta-se o conceito de Estado global, que não consta nos outros livros. Em Sociologia para jovens no século XXI, a referência ao Estado surge relacionada ao conceito de cidadania, de Marshall. A definição de Estado de Weber é empregada para diferenciar Estado e governo e na discussão sobre divisão de poderes. Por fim, no livro Sociologia, destaca-se que o Estado é objeto de interpretações controversas. São apresentadas as concepções de Engels, Marx, Weber, e de autores que não aparecem nos outros livros, como Gramsci, Althusser, Poulantzas e lanni - este último, vale assinalar, pertencente à tradição sociológica brasileira.

Como observado, todos os livros apresentam, ao menos, mais do que uma definição teórico-conceitual ao termo Estado, sendo essas definições fundamentadas em autores com perspectivas distintas. As definições de Marx e Weber foram verificadas em todos eles. Na maioria das obras, o conceito weberiano é priorizado, sendo mobilizado nas discussões a respeito das características centrais do Estado. Em alguns livros, a noção de Estado aparece adjetivada com vistas a destacar as suas diferentes formas de atuação. É possível notar, ainda, que a noção de Estado é, comumente, relacionada à temáticas como violência, cidadania e relações de poder. 
Não verificamos nos livros examinados qualquer defesa político-partidária e/ou doutrinária em proveito de uma concepção de Estado. Ao apresentar o Estado, transposto em forma didática, como objeto de estudo sociológico, os livros priorizam a diversidade do aparato teórico-conceitual construído pelas ciências sociais. Demonstram, por fim, que o conceito de Estado, em suas diferentes acepções científicas, pode ser empregado para a análise e compreensão de muitas questões postas no mundo contemporâneo.

\section{REFERÊNCIAS}

ARAÚJO, S. M.; BRIDI, M. A.; MOTIM, B. L.

Sociologia. São Paulo: Scipione, 2013.

BARDIN, L. Análise de conteúdo. Lisboa: Edições

70, 2002.

BODART, C. N.; SOUZA, E. D. Configurações do ensino de sociologia como um subcampo de pesquisa: análise dos dossiês publicados em periódicos acadêmicos. Ciências Sociais Unisinos, v. 53, n. 3, p.543-557, 2017. https://doi.org/10.4013/csu.2017.53.3.14

BOMENY, H. et al. Tempos modernos, tempos de sociologia: ensino médio. 2. ed. São Paulo:

Editora do Brasil, 2013.

BRASIL. Ministério da Educação. Guia de livros didáticos: PNLD 2015: Sociologia: ensino médio. Brasília: Ministério da Educação, Secretaria de Educação Básica, 2014.

CHARAUDEAU, P. Linguagem e discurso: modos de organização. São Paulo: Contexto, 2016.

FLORÊNCIO, M. A. L. Algumas reflexões sobre o livro didático de Sociologia e sua importância para a transposição didática do saber escolar. In: BODART, C. N.; LIMA, W. L. D. (Orgs.). $O$ ensino de Sociologia no Brasil. Maceió: Editora Café com Sociologia, 2019.

HANDFAS, A. Os livros didáticos de Sociologia.

Revista Coletiva, v. 1, p. 50-55, 2013.

MACHADO, I. J. R; AMORIM, H.; BARROS, C. R. Sociologia hoje. 1. ed. São Paulo: Ática, 2013.
OLIVEIRA, L. F; COSTA, R. C. R. Sociologia para jovens do século XXI. 3. ed. Rio de Janeiro: Imperial Novo Milênio, 2013.

TOMAZI, N. D. Sociologia para o ensino médio. 3. ed. São Paulo: Saraiva, 2013. 